\title{
PENGEMBANGAN PAUD MELALUI PELATIHAN KETERAMPILAN \& KREATIVITAS DI KELURAHAN SIWALANKERTO, KECAMATAN WONOCOLO, SURABAYA
}

\author{
Mariana Wibowo $^{1}$, Astri Indrawati Gunawan ${ }^{1}$, Yiawla Ismarch Priadi ${ }^{1}$ \\ ${ }^{1}$ Fakultas Seni dan Desain, Program Studi Desain Interior, Universitas Kristen Petra \\ Jl. Siwalankerto 121-131, Surabaya 60236 \\ * Penulis korespondensi; E-mail: mariana_wibowo@petra.ac.id
}

\begin{abstract}
Abstrak: Para guru (bunda) Pendidikan Anak Usia Dini (PAUD) diharapkan memiliki kemampuan untuk membuat seorang anak nyaman di PAUD, mampu memberikan pendidikan yang sesuai dengan perkembangan kecerdasan si anak serta dapat mengembangkan metode dan media belajar untuk anak usia dini secara tepat dan efisien. Stimulus yang diberikan bunda PAUD melalui kegiatan bermain sambil belajar, membuat anak dapat menyerap ilmu dan mengembangkan potensinya, sehingga memiliki kualitas yang bagus, cerdas berkarakter, berani, kreatif berkepribadian dan berakhlak mulia, untuk akhirnya siap menempuh pendidikan ke jenjang yang lebih tinggi. Disinilah letak penting peran bunda PAUD dalam membimbing anak didiknya guna mengembangkan potensi yang dimiliki si anak dengan memanfaatkan momentum masa keemasan perkembangan otaknya dengan pengetahuan dan ketrampilan yang dimiliki para bunda PAUD serta melatih motoric dan sensorik anak usia dini. Untuk menjawab kebutuhan inilah, Program studi Desain Interior Universitas Kristen Petra mengadakan kegiatan pelatihan keterampilan membuat art \& craft tangan dan elemen desain interior melalui kegiatan abdimas (Pengabdian Masyarakat) dengan memberikan pelayanan kepada masyarakat, khususnya bagi bunda-bunda PAUD di Kelurahan Siwalankerto, Surabaya. Pada pelaksanaan kegiatan Abdimas ini, subyek pelatihan dilatih untuk mampu mengembangkan ketrampilan dan kreatifitas bunda PAUD dalam membuat beberapa produk dengan memanfaatkan material yang mudah ditemukan dan ekonomis di lingkungan sekitar. Hasil produk ketrampilan bunda PAUD ini dapat digunakan untuk pengembangan desain interior ruang PAUD di Siwalankerto, Surabaya.
\end{abstract}

Kata kunci: Elemen interior, abdimas, PAUD, Siwalankerto.

\begin{abstract}
Teacher for early childhood education in Indonesia, called PAUD, expected to have ability to make a child comfortable at school, can give education that are suitable for children intelligence development and also can develop methods and study media for early childhood effectively and efficiently. This expectation including their motoric and sensoric ability. This motoric and sensoric development from the teachers of early childhood education can be given from learning while they are playing and doing something. It can give the children can get the education and develop their ability, so they can have a good quality, smart and have a good character, brave, and creative, so for the future they can continue to higher education better. This is the phase that a teacher plays their important role to lead the children in their golden age with the creativity and knowledge. To answer this need, Petra Christian University make an art and craft workshop by hand dan interior design element through this community service for the teachers in early childhood school called PAUD in Siwalankerto area. Throgh this community service, we teach the teachers how to make art \& craft and interior design elements using their creativity and materials which are easy to find in the their environment. The result for this community servive can be used for interior design development also in their school in Siwalankerto area, Surabaya.
\end{abstract}

Keywords: Interior'element, community service, early childhood education, Siwalankerto.

\section{PENDAHULUAN}

Pendidikan kegiatan seni dan kerajinan tangan anak usia dini memiliki banyak manfaat. Karena pada masa ini anak-anak sedang berada dalam suatu masa yang disebut dengan periode golden age.

Periode golden age adalah suatu periode dimana seluruh potensi anak-anak lebih peka terhadap pertumbuhan dan perkembangan aspek 
fisik, kognitif, sosioemosional, kreativitas, bahasa dan komunikasi. Periode golden age di Indonesia seperti yang tercatat dalam Undang-Undang Republik Indonesia Nomor 20 tahun 2003 tentang Sistem Pendidikan Nasional pada Pasal 1 ayat 14 adalah bagi anak sejak dari lahir hingga usia 6 tahun.

Sedangkan menurut NAEYC (National Association for The Education of Young Children), pendidikan anak usia dini adalah bagi anak usia 0 hingga 8 tahun yang mendapatkan layanan pendidikan di taman penitipan anak, penitipan anak dalam keluarga (family child care home), pendidikan prasekolah baik negeri maupun swasta, taman kanak-kanak (TK) dan sekolah dasar (SD) (Aisyah, 2011).

Pada pendidikan kegiatan seni dan kerajinan tangan anak usia dini terdapat beberapa metode pembinaan untuk mengoptimalkan tumbuh kembang anak, salah satu metodenya adalah melalui kegiatan seni, yakni metode pembinaan kreativitas. Metode pembinaan kreativitas adalah pembinaan dalam hal kemampuan mencipta, menanggapi persoalan, mudah menyelesaikan diri di setiap situasi, memiliki keaslian (orisinalitas maupun kepribadian) serta memiliki kemampuan berpikir secara menyeluruh. Pada pendidikan kegiatan seni dan kerajinan tangan anak usia dini juga membantu anak-anak mengembangkan aspek motorik halus dan kognitif.

Oleh karena itulah peran serta ibu guru dalam membimbing anak-anak melalui mata pelajaran kesenian tidak boleh dipandang remeh. Terutama pada anak usia dini, yang lebih tertarik dan lebih mudah menerima pengetahuan baru melalui media bentuk dan warna.

Dan melalui kegiatan Abdimas ini diharapkan agar para pelaku abdimas mampu membagikan pengalaman dan pengetahuan menciptakan produk art \& craft serta elemen interior yang bermanfaat dan menarik, yang juga dapat dipraktekkan dengan anak-anak secara aman.

\section{Perkembangan Kognitif dan Motorik Anak}

Penggunaan warna cerah merangsang kreativitas anak (Weinstein dan Thomas, 1987). Mengenalkan warna dan bentuk sejak usia dini dapat mengembangkan kecerdasan, bukan hanya mengasah kemampuan mengingat, tapi juga imajinatif dan artistik, pemahaman ruang, keterampilan kognitif. Serta pola pikir kreatif.

Desain dengan warna yang menarik diharapkan dapat menarik minat anak untuk belajar dengan lebih maksimal. Seperti dalam pendapat bahwa menyebut, mengklasifikasi-kan, membedakan, dan menghitung warna merupakan kemampuan kognitif-logika anak yang digunakan sebagai dasar melakukan asimilasi, adaptasi, dan akomodasi terhadap lingkungan dan situasi baru. Kemampuan tersebut membentuk skema baru, sehingga anak memiliki kemampuan aktivitas memproses informasi (Rasyid, Mansyur, dan Suratno. 2009)

Perkembangan motorik adalah perkembangan yang terkait dengan semua gerakan yang dapat dilakukan oleh tubuh dalam melakukan sesuatu yang membutuhkan koordinasi atau berfungsinya bagian-bagian tubuh melalui kegiatan pusat syaraf, urat syaraf dan otot terkoordinasi. Keterampilan motorik anak terdiri atas keterampilan motorik kasar dan keterampilan motorik halus (Hurlock, 1998). Kegiatan seni dan kerajinan tangan anak usia dini membantu mengembangkan aspek kognitif dan motorik halus pada anak-anak. Kegiatan seni dan kerajinan tangan snak usia dini (PAUD) mengajak anak mengamati, meraba, mencium, menggunakan dan memperlakukan alat dan bahan untuk menghasilkan sesuatu. Dan di sekolah yang breperan penting mengajarkan hal ini adalah para guru. Oleh karena itu para guru kesenian hendaknya terus menambah kretifitas agar selalu dapat menciptakan karya-karya baru dan anak-anak tidak mudah bosan serta memperoleh pengetahuan dan pengalaman baru.

\section{METODE PELAKSANAAN}

Metode yang digunakan untuk menjawab permasalahan atau mencapai tujuan kegiatan Abdimas ini adalah dengan workshop melalui tahap-tahap sebagai berikut:

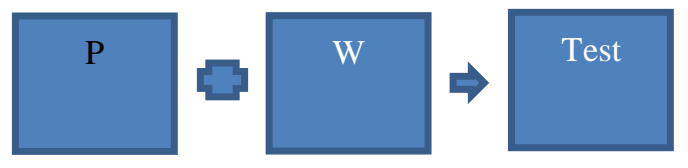

\section{Persiapan (Preparation - P)}

Persiapan dilakukan dengan mengundang perwakilan lima PAUD diarea Siwalankerto ini untuk mengikuti workshop yang diadakan di kampus UK. Petra. Pada tahapan ini, tim abdimas melakukan diskusi kelompok bersama semua bunda PAUD di Kelurahan Siwalankerto untuk mendapatkan data kebutuhan pelatihan sesuai dengan kondisi PAUD di Kelurahan Siwalankerto. Kemudian tim abdimas membagi tim bunda PAUD dalam 3 kelompok kecil dengan masing-masing akan mengikuti workshop pembuatan art \& craft dan elemen interior. Dari hasil diskusi kelompok, masing-masing kelompok diputuskan membuat 3 jenis ketrampilan yang berbeda, yaitu, clock \& storage, lampu gantung, dan signage ruang PAUD. Kemudian masing-masing kelompok abdimas menyiapkan material/bahan dan peralatannya. 


\section{Pelaksanaan (Workshop - W)}

Pelaksanaan Abdimas ini dilaksanakan di gedung Radius Prawiro UK. Petra lantai 3. Workshop diawali dengan penyampaian materi oleh tim dosen pengabdi, dibantu oleh 6 mahasiswa Program Studi Desain Interior, kemudian dilanjutkan dengan workshop yang dimana bunda-budna PAUD akan mempraktekkan yang sudah diajarkan, yang sebelumnya telah dibagi dalam kelompok-kelompok kecil. Pelaksaan workshop dibagi menjadi 4 sesi, dibutuhkan minimum 10 jam yang dilakukan satu kali dalam satu minggu, yaitu setiap hari kamis dalam 3 bulan.

Materi workshop adalah pelatihan pembuatan:

1. Clock \& storage "Beehive Clock"

2. Lampu gantung "Lampion"

3. Lampu gantung "Benang"

4. Signage ruang PAUD

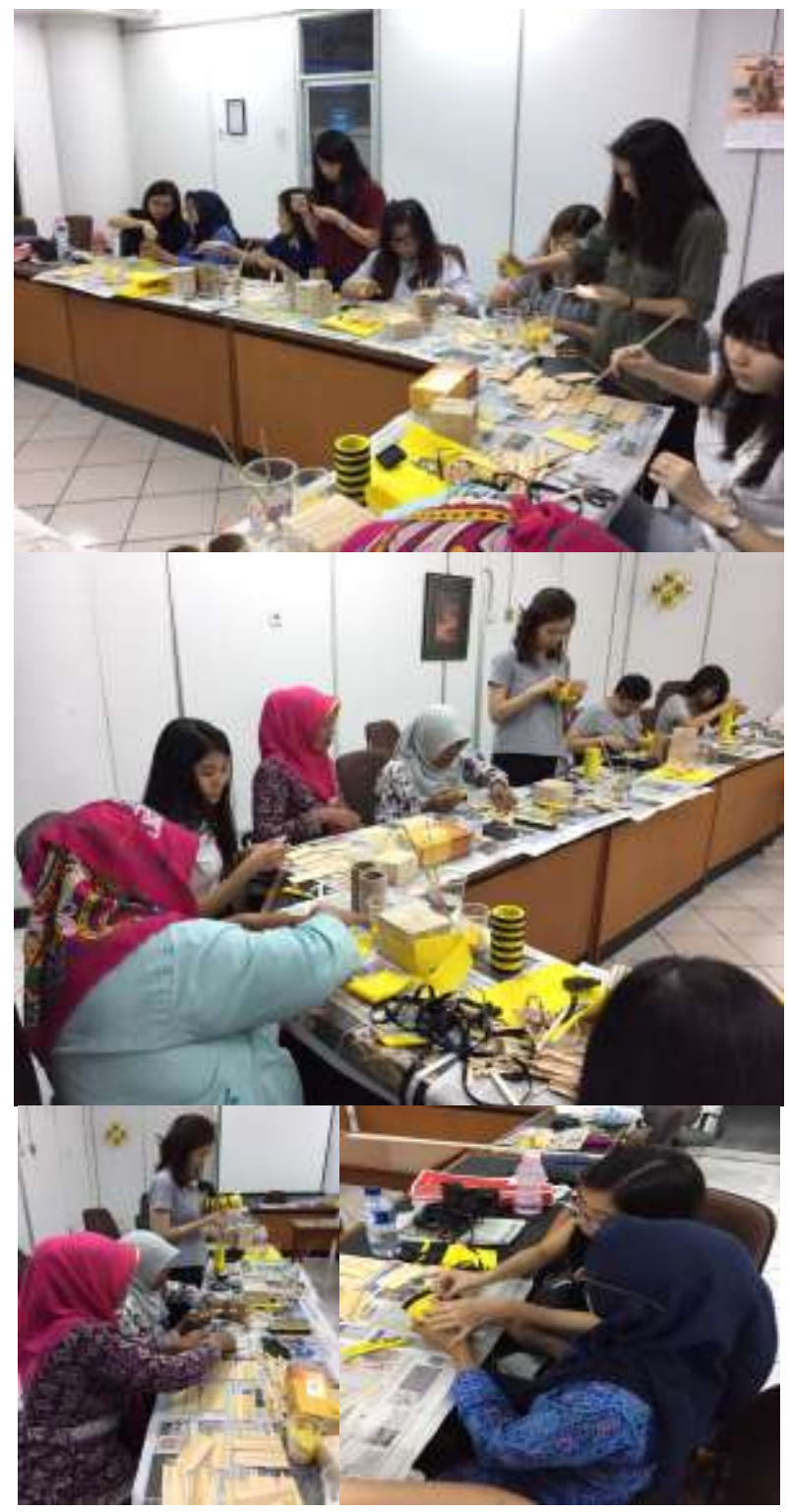

Gambar 1. Kegiatan workshop peserta

\section{Penerapan di siswa PAUD (Test)}

Pada tahapan ini, para bunda PAUD mengaplikasikan teknik pembelajaran pada siswa-siswa PAUD di PAUD masing-masing. Aplikasi ketrampilan ini dilakukan dengan cara mengikutsertakan para siswa PAUD untuk membuat ketrampilan bersama dengan bunda-bunda PAUD. Pembuatan art \& craft dan elemen interior ini melatih motoric dan sensorik anak sekaligus hasil pembuatannya dapat digunakan untuk mengembangkan desain interior ruang kelas PAUD di sekolah PAUD masing-masing.

\section{HASIL DAN PEMBAHASAN}

Materi pertama adalah pelatihan membuat ketrampilan berupa clock \& storage dengan tema "Beehive Clock". Pemilihan tema ini dikarenakan anak-anak menyukai sesuatu yang lucu dan menarik. Beehive (sarang lebah) dipilih karena fungsi storage adalah menyimpang barang-barang berharga, sama halnya dengan sarang lebah menyimpang madu yang berharga didalamnya. Pemilihan tema untuk hal yang disukai anak usia dini hendaknya tidak sekedar indah dipandang, melainkan dapat memberi edukasi atau pesan positif bagi anak usia dini. Salah satunya adalah jam dinding yang juga berfungsi sebagai tempat pensil/peralatan tulis. Jam ini membuat anak usia dini dapat belajar untuk mengenal waktu. Selain itu, tempat alat tulis ini membantu anak untuk membiasakan diri menyimpan barang-barangnya dengan rapi. Jam ini akan terlihat lebih indah apabila banyak peralatan tulis di dalamnya. Karena keberagaman warna alat tulis dan pensil warna inilah yang membuat jam tersebut dapat terlihat lebih menarik.

Jam ini berbentuk menyerupai sarang lebah, sehingga terlihat unik. Warna yang digunakan adalah kuning dan putih. Warna kuning secara psikologis dapat meningkatkan konsentrasi anak, sedangkan warna putih merupakan warna netral yang memberi kesan tenang dan sejuk. Tempat alat tulis berwarna kuning dan hitam yang sesuai dengan warna lebah. Ditambah dengan aksesoris mata dan antena agar lebih menyerupai lebah.

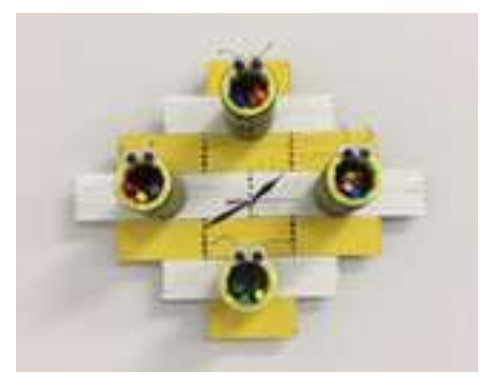

Gambar. 2. Beehive Clock. 


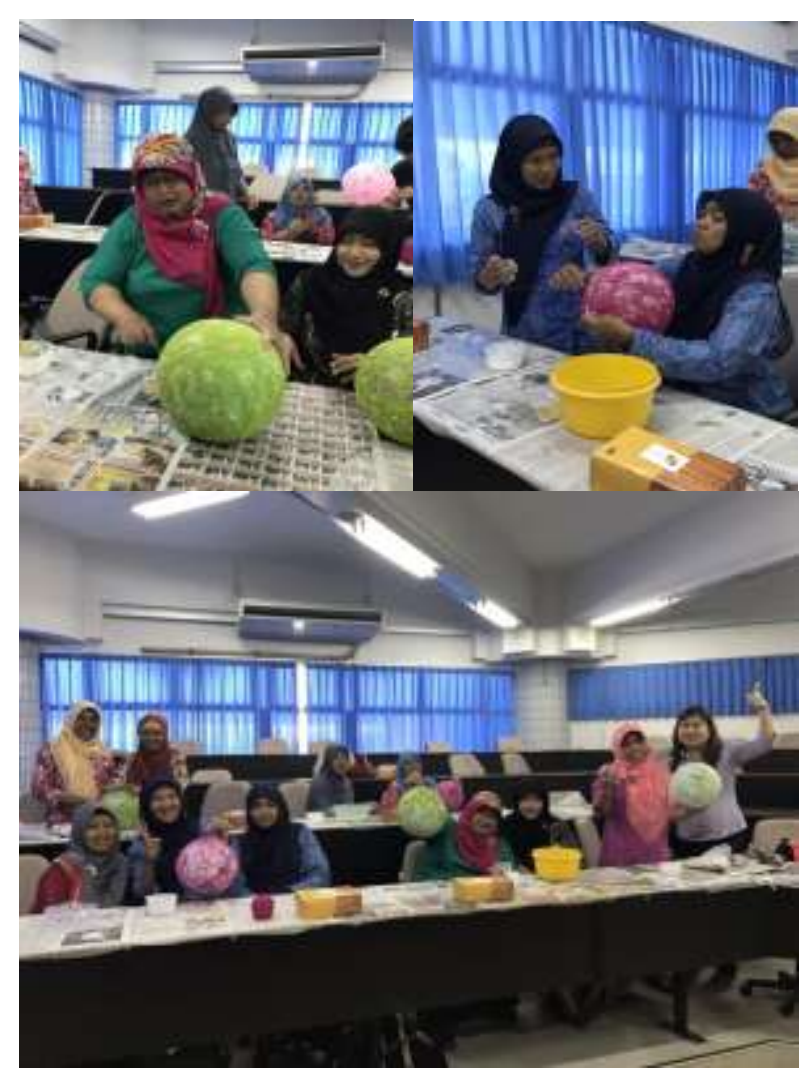

Gambar. 3. Proses pembuatan Lampu Benang.

Karya ketrampilan ini adalah karya yang ramah lingkungan juga karena disarankan menggunakan reuse material yaitu stik es krim bekas yang sudah dikeringkan dan karton plastic wrap. Stik es krim digunakan sebagai penampang jam sedangkan karton plastic wrap digunakan untuk tempat alat tulis. Karya ini membutuhkan 2x84 stik es krim ditambah dengan penguat sekitar 16 stik, serta 4 buah karton plastic wrap yang berukuran $12 \mathrm{~cm}$. Bahan pendukung lainnya adalah 1 mesin jam, 1 baterai AA, 4 kain flanel kuning, pita warna hitam, 8 mata, 8 "antena" yang menggunakan putik plastik warna hitam, kayu balsa, cat kuning, cat putih, lem uhu, lem tembak, dan gunting.

Cara pembuatannya adalah setiap 5 buah stik es krim dijajar ke samping dan dilekatkan menggunakan lem uhu menjadi 1 set. Set pertama tersebut diperlukan sebanyak 12 kali. Selain itu, adapula tambahan 4 set kedua dimana setiap set terdiri dari 6 stik es krim yang dilekatkan satu sama lain. Warna kuning diberi pada 8 set pertama, sedangkan warna putih pada 4 set pertama dan 4 set kedua. Setelah selesai mengecat, barulah menyatukan set-set tersebut membentuk menyerupai beehave. Setiap set diarahkan mendatar. Susunan dari atas adalah 1 set pertama kuning, 2 set pertama putih, 3 set pertama kuning, 4 set kedua putih, 3 set pertama kuning, 2 set pertama putih, dan 1 set pertama kuning. Pengulangan susunan ini membuat jam terlihat simetris dan rapi. Susunan ini dibuat 2x karena digunakan untuk bagian depan dan bagian belakang sehingga lebih kuat. Ketika melekatan kedua bagian itu, di tengahnya diberi penguat berupa stik es krim yang dilekatkan secara diagonal menggunakan lem tembak.

Jika penampang jam sudah jadi, sekarang waktunya untuk membuat tempat alat tulis. Langkah pertama adalah dengan menempelkan kain flanel kuning di sekeliling karton plastic wrap menggunakan lem uhu. Setelah itu barulah menempelkan pita hitam secara melingkar mengikuti bentuk karton tersebut. Pita hitam diulang sebanyak 4x hingga menyerupai badan lebah. Sentuhan terakhir yaitu dengan menambahkan mata dan antena lebah agar lebih terlihat mirip lebah. Sebelum menempelkan karton ke penampang jam, harus menyiapkan tempat mesin jam. Tempat ini dibuat dengan membuat lubang di tengah penampang jam. Lubang ini cukup susah dibuat karena stik es krim rentan patah dan rusak. Sehingga pembuatan lubang ini hanya menggunakan ujung gunting yang diputar secara perlahan.

Setelah mesin jam terpasang, barulah tempat alat tulis dipasang. Tempat tersebut ditempelkan pada bagian atas, kanan, bawah, dan kiri, dimana mewakili angka 3, 6, 9, dan 12. Agar karya ini dapat digantung di dinding, diperlukan kayu balsa yang ditempel membentuk segitiga di bagian belakang penampang. Langkah terakhir yaitu dengan memasang baterai yang membuat jam ini dapat berfungsi dengan baik.

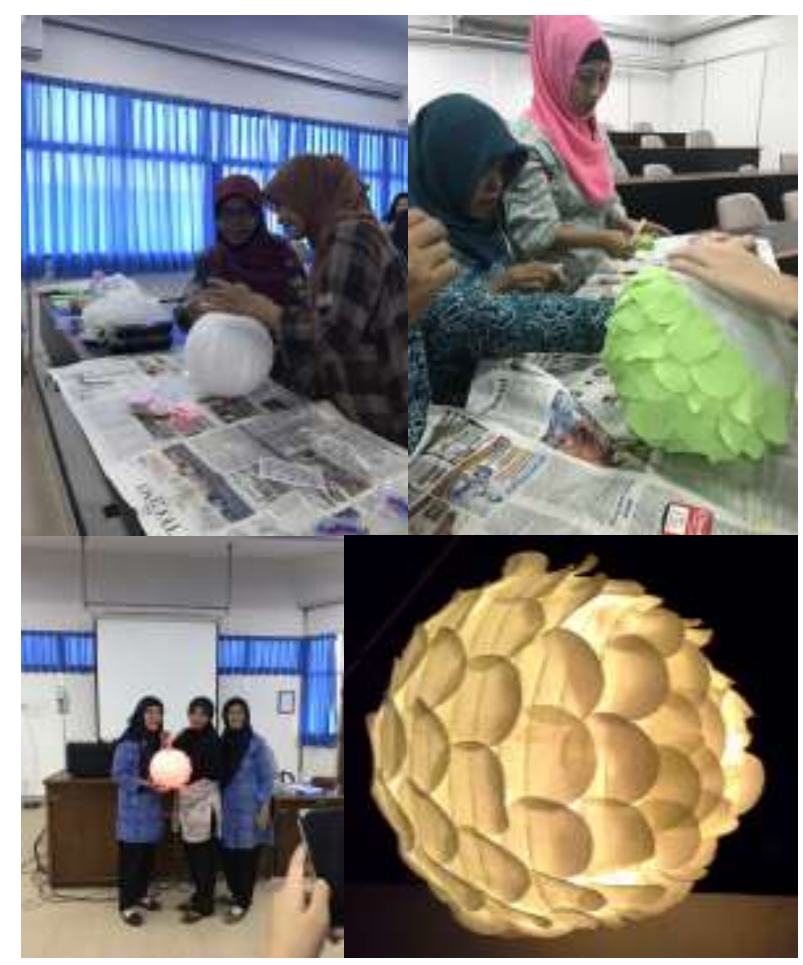

Gambar 4. Proses pembuatan Lampu Lampion. 


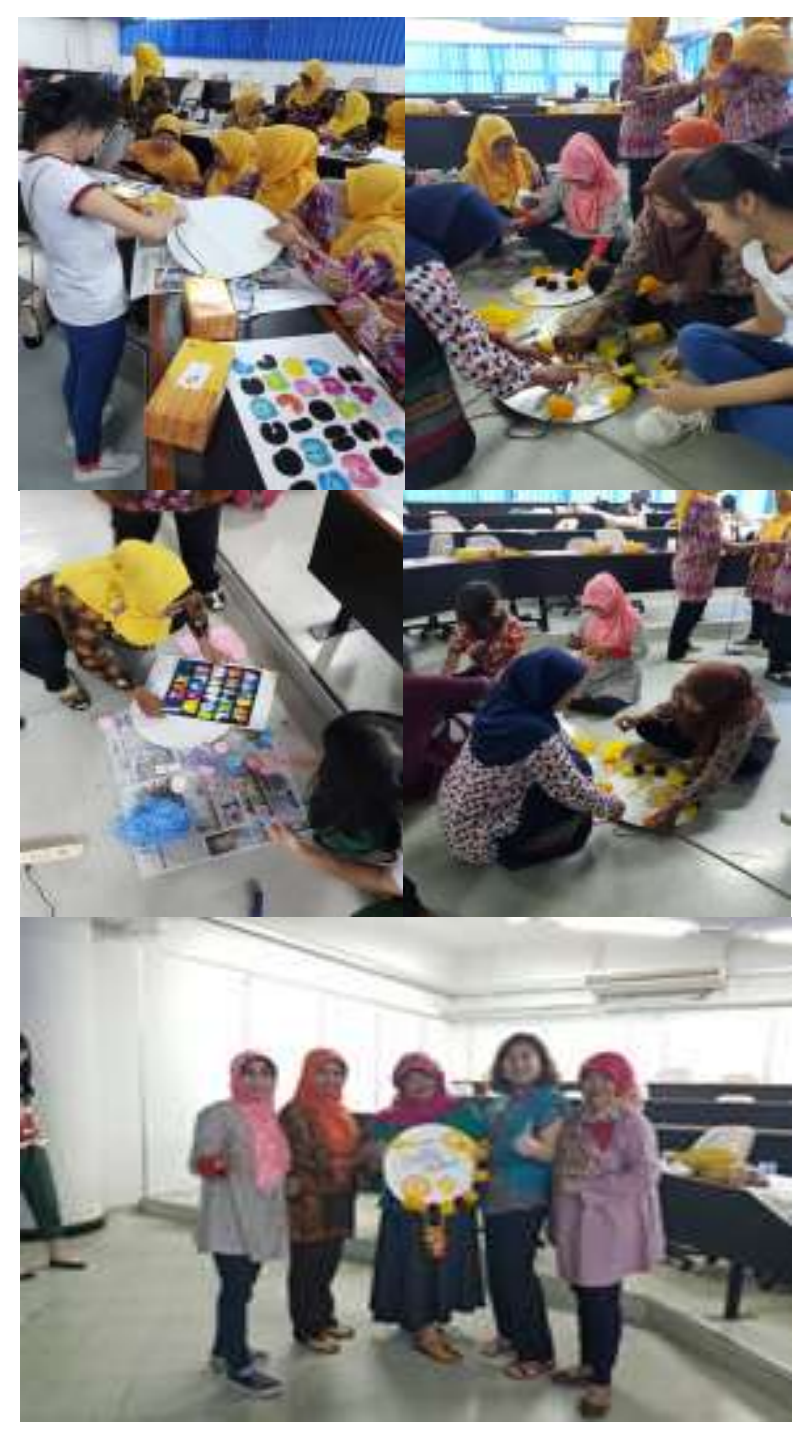

Gambar 5. Proses pelatihan pembuatan Signage

Dari langkah-langkah di atas, para bunda PAUD yang merasa penggunaan stik es krim sangat mudah didapat dan ekonomis. Dan hal ini mencapai tujuan utama karya yaitu memanfaatkan barang-barang yang sudah terbuang menjadi barang yang lebih bermanfaat. Para bunda PAUD ini menyukai bentuk dan warna jam ini karena hasil jadinya lucu dan unik. Penggunaan warna kuning yang cerah bertujuan untuk menarik perhatian anak-anak agar menggunakan karya ini. Pembuatannya cukup mudah, sehingga diharapkan ibu-ibu PAUD dapat berkreasi membuat dan mengembangkan kreativitas jam dinding yang sekaligus berfungsi sebagai tempat penyimpanan alat tulis.Penerapan ini di PAUD masing-masing dengan melibatkan siswa PAUD dapat melatih kreativitas maupun motoric dan sensorik anak.

Materi kedua dan ketiga adalah pelatihan ketrampilan membuat lampu gantung. Lampu pertama yang dibuat adalah lampu dengan menggunakan material benang, material yang dibutuhkan dalam workshop ini adalah bola lampu, kabel listrik, balon, benang wol dan lem putih. Cara membuatnya yakni pada langkah pertama yang dilakukan para bunda PAUD ini adalah meniup balon sesuai dengan ukuran yang diinginkan. Kemudian melapisi balon dengan lem putih yang sedikit dicampur dengan air. Lalu lilitkan benang ke balon hingga menutupi balon sambil sesekali tambahkan lem ke lilitan benang. Setelah itu menunggu lem hingga kering, kemudian letuskan balon yang ada di dalam benang. Potong bagian atas benang untuk memasukkan lampu. Maka, lampu benang sudah dapat digunakan.

Lampu kedua adalah lampu lampion dan kertas krep. Material yang dibutuhkan adalah bola lampu, kabel listrik, lampion diameter $20 \mathrm{~cm}$, kertas krep dan lem putih. Gunting, mal/cetakan (untuk membuat pola di atas kertas krep), dan kertas koran. Langkah pertama yang dilakukan untuk membuat lampion kertas ini adalah menentukan diameter lingkaran yang akan digunakan untuk menutupi seluruh lampion kertas. Untuk lampion kertas diameter $20 \mathrm{~cm}$ dapat menggunakan lingkaran diameter $6 \mathrm{~cm}$. Kemudian buat cetakan lingkaran sesuai ukuran tersebut, lalu membuat pola lingkaran di kertas krep. Setelah itu, potong kertas krep yang telah dipola bentuk lingkaran. Pengerjaan pembuatan pola bulat ini dibantu oleh tim mahasiswa sehingga setelah seluruh lingkaran dipotong, lingkaran-lingkaran tersebut oleh para bunda PAUD kemudian ditempel mengelilingi lampion perbaris hingga membentuk seperti sisik ikan. Kemudian pasang lampu pada lampion. Lampion telah selesai dan dapat digunakan. Sebelumnya pemotongan kertas krep berbentuk bulat dengan diameter $6 \mathrm{~cm}$ oleh mahasiswa ini dilakukan untuk memudahkan pemasangan dan efisiensi waktu pembuatan.

Pembuatan elemen interior lampu gantung ini menarik minat para bunda PAUD di Kelurahan Siwalankerto Surabaya. Menurut mereka proses pembuatannya mudah, dan aman, sehingga bisa diparktikkan bersama dengan anak-anak. Bahkan beberapa bunda paud mengatakan akan mencoba untuk menggunakan material yang banyak dilingkungan mereka seperti kulit bawang agar lebih menarik.

Materi terakhir adalah pelatihan pembuatan signage untuk ruang PAUD. Papan signage merupakan salah satu objek yang sering dijumpai di lingkungan pendidikan, yang berfungsi sebagai penanda suatu tempat.

Untuk lingkup pendidikan usia dini (PAUD) papan ini dapat dibuat lebih menarik agar dapat membantu konsep visualisasi anak menjadi lebih beragam. Bahan yang digunakan adalah: papan tripleks melamin $0,3 \mathrm{~mm}$ (untuk white board) dibentuk bulat dengan melibatkan siswa PAUD di PAUD masing-masing dalam pembuatan ketram- 
pilan ini dapat meningkatkan kreativitas, kecintaan mereka terhadap PAUD atau ruang kelas mereka sehingga mereka akan lebih semangat untuk pergi bersekolah.

\section{KESIMPULAN}

Dari kegiatan ini dan berdasarkan hasil diskusi dengan para bunda PAUD yang merupakan guru atau tenaga pengajar dari perwakilan 5 PAUD di daerah Siwalankerto ini dapat disimpulkan bahwa:

1. Kegiatan Abdimas ini ternyata bermanfaat dan dilakukan dengan cukup antusias, bahkan para bunda PAUD ini mulai berpikir kreatif dengan mencari material pengganti dari material aawal yang dikenalkan oleh tim abdimas. Dari kegiatan ini para bunda PAUD ini terlihat mulai terbuka dan berani mengembangkan kreativitas.

2. Pemberdayaan para bunda pengajar 5 PAUD di Kelurahan Siwalankerto dengan metode workshop dan test dapat menyadarkan para bunda PAUD dalam melibatkan siswa PAUD dalam ketrampilan dapat mengembangkan kemampuan motoric dan sensorik serta kreativitas PAUD. Hasil yang dihasilkannya pun dapat berguna dan memiliki nilai fungsi untuk pengembangan desain interior ruang kelas PAUD masingmasing (tidak hanya jadi benda pajang / yang tidak memiliki nilai fungsi).
3. Kegiatan abdimas yang telah dilaksanakan telah membawa manfaat bagi bunda pengajar PAUD, siswa PAUD dan desain interior institusi PAUD masing-masing yang terlibat.

\section{SARAN}

Para bunda pengajar PAUD ini juga diharapkan dapat berperan aktif dalam memberi ilmu kepada PAUD yang lain. Yang secara tidak langsung, akhirnya kegiatan ini dapat memberi semangat dan dampak positif bagi PAUD yang lain di sekitar Siwalankerto Surabaya.

\section{DAFTAR PUSTAKA}

Aisyah, Siti, et. Al. (2011). Perkembangan dan Konsep Dasar Pengembangan Anak Usia Dini. Jakarta: Universitas Terbuka.

Hurlock, E.B. (1998). Perkembangan anak jilid 1. Jakarta: Erlangga.

Rasyid, H., Mansyur \& Suratno. (2009). Asesmen perkembangan anak usia dini. Yogyakarta: Multi Pressindo.

Wavin. (2017, Juni 22). Arti dan Tren DIY (Do It Yourself) pada Kehidupan Sehari- Hari. Diunduh dari Wavin: http://www.wavin.co.id/artidan-tren-diy-do-it-yourself-pada-kehidupansehari-hari/

Weinstein, Carol. S. dan Thomas G. David. (1987). Spaces for Children The Built Enviroment and Child Development. New York: Plenum. 